\title{
Evidence of forage distance limitations for small bees (Hymenoptera: Apidae)
}

\author{
Ivan R. WRIGHT ${ }^{1}$, Stuart P.M. ROBERTS ${ }^{2}$ and Bonnie E. COLLINS ${ }^{1}$
}

\author{
${ }^{1}$ Shotover Wildlife, 15, Blenheim Way, Horspath, Oxford, OX33 1SB, UK; e-mail: irwright@shotover-wildlife.org.uk \\ ${ }^{2}$ 1, Waterloo Road, Salisbury, SP1 2JR, UK; e-mail: spmr@msn.com
}

Key words. Hymenoptera, Apidae, ground-nesting bees, forage, flight distance, partial habitats, habitat fragmentation

\begin{abstract}
The distribution of ground-nesting bees was investigated using transects of water traps in a mosaic of nesting and forage habitats at Shotover Hill in Oxfordshire, UK. The site includes a large area of ground-nesting bee activity and is adjoined on three sides by floristic hay meadows. This study showed that the females of small bee species $(<1.5 \mathrm{~mm}$ intertegular span) that were foraging in the hay meadows demonstrated a functional limitation to their homing range. The abundance of small bees declined rapidly with increasing distance from areas of high density nesting; declining more rapidly than might be expected from uniform dispersal into the surrounding landscape. By modelling the occurrence of bees along each transect it was found that the probability of observing a small bee in the hay meadows was reduced to $10 \%$ at a distance of $250-370 \mathrm{~m}$ from the nesting habitat. The result emphasises the scale on which habitat fragmentation will begin to impact upon bee diversity, and the relative contribution of managed "pollen and nectar" strips to areas of nesting habitat.
\end{abstract}

\section{INTRODUCTION}

The importance of wild bees as pollinators of crops and wild flora is widely appreciated (Corbet et al., 1991; Williams, 1996; Holzschuh et al., 2007) and yet the contribution and dynamics of the many different species towards pollination is much less frequently reported (Westrich, 1996; Kremen et al., 2002) and have tended to focus on larger bee species (Osborne et al., 1999; Cresswell et al., 2000; Walther-Hellwig \& Frank1, 2000; Osborne et al., 2008). There is some justification for this bias as the larger bees have the capacity to forage and transfer pollen over great distances (Gathmann et al., 1994). Some species of solitary bee, e.g. Megachilinae spp., have been more extensively studied because of their importance for the spring pollination of fruit trees (Torchio, 1976; Bosch et al., 2006; Krunić \& Stanisavljević, 2006; Guedot et al., 2009). Smaller solitary and social bee species have received much less attention, even though their species diversity is greater than larger bees, and are often in greater abundance (Westphal et al., 2008).

With the exception of the cleptoparasitic species, all female bees prepare a nest in which each cell is stocked with pollen before laying an egg within. Consequently at the time of nest building, as a central place forager, the provisioning bee must forage strategically in the landscape for pollen, and make a number of journeys depending upon the total volume of pollen required and the bee's carrying capacity in flight (Westrich, 1996; Franzén \& Larsson, 2007). Foraging strategy is complex (Goulson, 2010) but the energy required for each journey will at least depend upon whether the pollen demand can be readily satisfied by a general source of locally abundant flora or whether a particular species or family of flower is required. In the latter case, greater flight capacity is required where the specific flora is either sparsely distributed or some distance away in sufficient abundance. In some cases the nesting and foraging habitats may be close to one another; however in many cases the nesting requirement, such as a sandy soil, sunlit slope or vacated beetle hole, may be some distance from the pollen source. Therefore, in conserving for wild bees or managing for their pollination potential, it is important to recognise that each species may require two or more partial habitats for nesting and foraging (Westrich, 1996) and the distances between habitats will be a critical factor for species viability (Westrich, 1996; Williams \& Kremen, 2007; Goulson et al., 2010; Jha \& Kreman, 2012).

On any scale, as connectivity between habitats becomes weakened by fragmentation of the natural landscape, the viability of central place foragers becomes threatened as the fragmentation approaches the limits of their capacity to travel. In the case of foraging bees it is the physical size of the bee that limits the effective distance that a species is able to travel for pollen; the larger the bee, the greater will be the distance it may forage from its nesting site (Gathmann et al., 1994; van Nieuwstadt \& Ruano Iraheta, 1996; Gathmann \& Tscharntke, 2002). Therefore as partial habitats become increasingly isolated and distant from each other, notwithstanding their quality, it will be the smaller bees that are most disadvantaged (Araújo et al., 2004).

In previous work, the different methods of trying to estimate the maximum foraging ranges of different species of bee demonstrates both the difficulty and the aspiration to evaluate this critical statistic. An overview and objective comparison of methods is given by Greenleaf et al. (2007) who suggest that most methods are likely to indicate a shorter foraging range when compared to their optimised model of flight distances, and by an amount which may be associated with the particular method. The underlying problem is that most methods introduce an unnatural circumstance upon a natural landscape to allow for an obser- 
vation or measurement. For example: adding artificial tube nesting sites (Tscharntke et al., 1998) using movable feeding stations (van Nieuwstadt \& Rhoano Iraheta, 1996) or the homing of bees following translocation (Fabre, 1914; Gathmann \& Tscharntke, 2002; Guedot et al., 2009). Furthermore simplifying assumptions have to be made about the activities and diversions of the bees as they fly between their foraging and nesting sites. It has also been demonstrated that bees operating at distances that approach the limit of their flight range suffer from reduced brood productivity (Peterson \& Roitberg, 2006; Zurbuchen et al., 2010) suggesting that maximum flight distance may be a misleading statistic when considering the effects of habitat fragmentation and obligate long-range foraging. The diversity of these experimental methods does, however, provide a range of distance estimates that may converge towards a better understanding of foraging behaviour and the conservation requirements of bees.

In this study we have taken advantage of a particular landscape circumstance, where a natural sandy area with an abundance of ground-nesting bees is adjoined by several floristically diverse hay meadows. Consequently we have the opportunity to assess natural foraging distances by sampling within a landscape that is almost entirely undisturbed by experimental constraints; the only disturbance being the presence of the sampling devices.

\section{MATERIAL AND METHODS}

Data were collected at Shotover Hill, a small sandstone plateau $3 \mathrm{~km}$ east of Oxford, UK $\left(51^{\circ} 45^{\prime} 18^{\prime \prime} \mathrm{N}, 1^{\circ} 11^{\prime} 8^{\prime \prime} \mathrm{W}\right.$, altitude $171 \mathrm{~m}$ a.s.1.) which has been recognised for its diversity of aculeate Hymenoptera (bees, wasps and ants) for more than a century (Salzman, 1939; Steel, 1984; Wright \& Gregory, 2006). The area has significant exposures of sandy soil of the Whitchurch and Kimmeridge formations (Horton et al., 1995) which are very readily colonized by aculeates upon exposure (Gregory \& Wright, 2005). Over half of the UK aculeate fauna have been found here over time (Wright \& Gregory, 2006) with 219 species recorded between 1999 and 2012. The areas of highest aculeate diversity are on the upper part of the hill and mostly within "Brasenose Wood and Shotover Hill" Site of Special Scientific Interest (SSSI) (Fig. 1). The SSSI is managed by the Local Authority as a public amenity and has partially succeeded to secondary woodland and tall scrub. Consequently although the diversity of flora is good, the abundance is generally poor due to the predominance of closedcanopy woodland and scrub (see Fig. 1) and is likely to be somewhat limiting in its overall provision of pollen and nectar for invertebrates.

Adjoining the SSSI to the north, east and south are three hay meadows (Fig. 1) each differing in character, but all are cut each year in June or July. With the exceptions mentioned below, the dominant flora of the fields is very similar. Early pollen sources are Lamium purpureum Linnaeus (Lamiaceae), Taraxacum officinale agg. F.H. Wigg (Asteraceae) and Veronica chamaedrys Linnaeus (Plantaginaceae) followed by Trifolium repens Linnaeus (Fabaceae), Ranunculus spp. (Ranunculaceae), Vicia sativa Linnaeus (Fabaceae), Crepis spp. (Asteraceae), Lotus corniculatus Linnaeus (Fabaceae) and Heracleum sphondylium Linnaeus (Apiaceae).

The northern field is an old unimproved private meadow on free-draining sand which slopes slightly to the north, and which has not been cropped or grazed significantly for about 60 years.

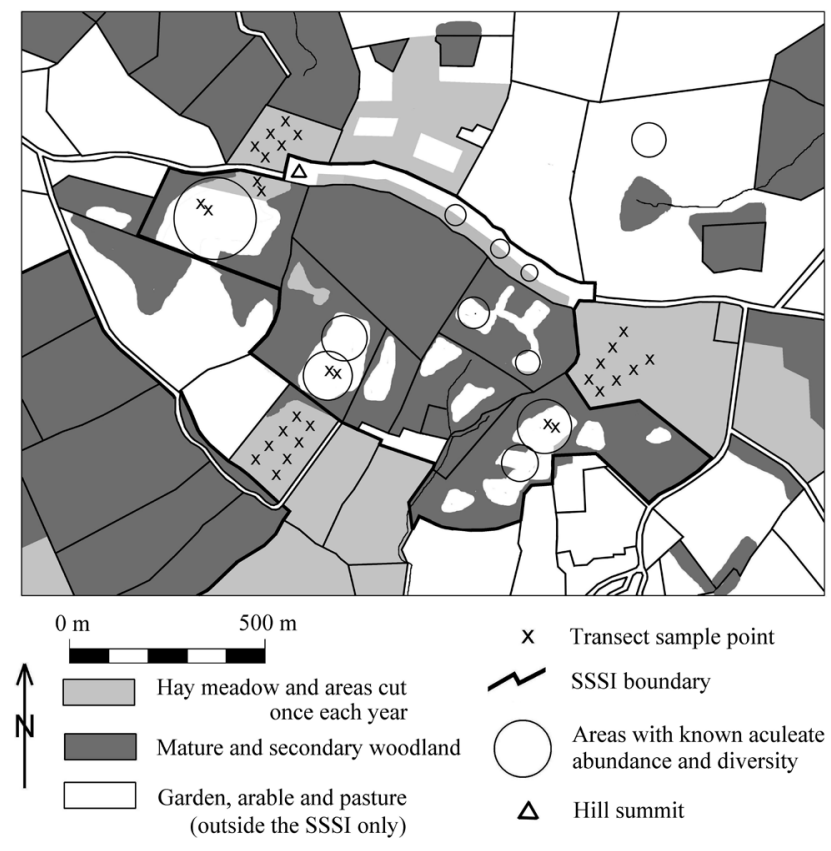

Fig. 1. A plan of Shotover Hill summit showing the habitats, the SSSI boundary and the sample points for ground nesting bees.

The sward of this mildly acidic field is somewhat unproductive for hay, and the flora is not especially abundant. Some bare soil is created by the burrowing activities of Talpa europaea Linnaeus (Talpidae). To the east of the SSSI is a tenanted "set-aside" field which is on the same free draining sand as the north field but with a negligible gradient. This field has not been cropped for about 30 years, but still retains a residual fertility with a strong growth of tall grasses each year. Consequently, compared to the other two fields this east field has a greater abundance of tall Asteraceae, such as Crepis biennis Linnaeus. There is some bare soil, mostly around the edges of the field. The southern field slopes gently to the south and is on a glacial deposit of clay-loam with impeded drainage in places. There is a little bare soil around the edges. This tenanted field was also set-aside from cropping about 30 years ago and has developed a diverse and reasonably abundant flora with a number of different Vicia spp., and the flora is consequently richer than the other two fields.

The predominant habitat ( $75 \%$ by area) in the vicinity of the SSSI and hay meadows is secondary woodland (Quercus robur Linnaeus, Betula pendula Roth and Crataegus monogyna Jacques) of typically 70 years growth. Other surrounding habitats are mature deciduous woodland $(10 \%)$, improved grass pasture $(10 \%)$ and a large private garden (5\%) (Fig. 1). However, within the sandy part of SSSI, and at about the same distance from each of the hay meadows, are three open areas of acidic grassland and heathland scrub where, through many years of prior observation, ground nesting aculeates are known to be particularly diverse and relatively abundant (Wright \& Gregory, 2006). Considering the juxtaposition of the surrounding geology and habitats, the three open areas are likely to be the nearest locations of abundant nesting to each of the three hay meadows, and the predominant source of soil-nesting bees to be found foraging in these fields. The open areas were therefore nominated as reference points from which to radiate the sample transects (Fig. 1).

Bees were sampled using yellow polythene water traps of 280 $\mathrm{mm}$ diameter, which were deployed on days with suitably warm and dry conditions. The traps were in place before 9:30am on the survey days and collected after 4:00 pm on the same day. On each day 30 traps were arranged in 6 transects with 5 sample points on 


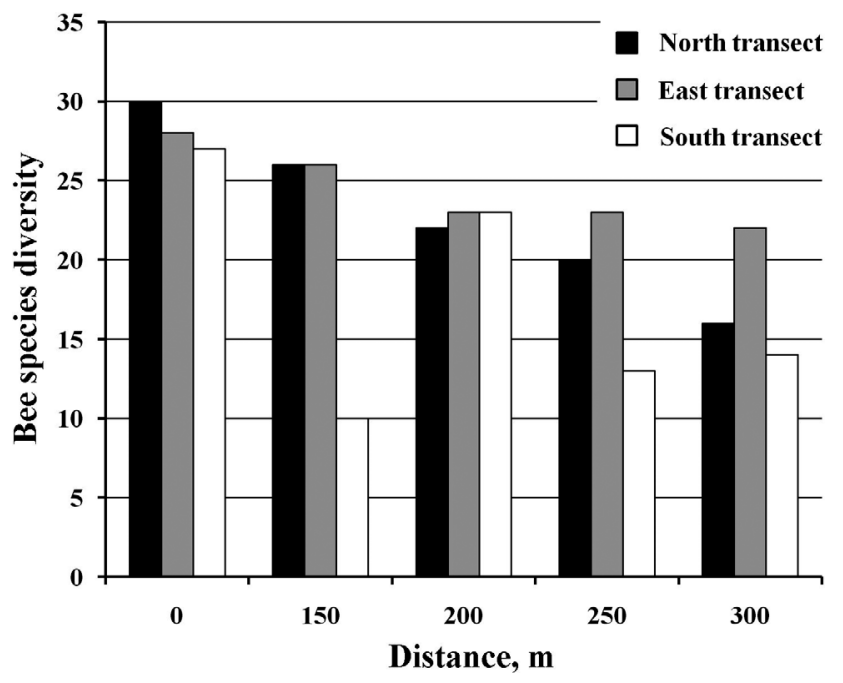

Fig. 2. Diversity of bees in each of three sample directions, 2010-2012 (paired transects combined).

each, starting from within the SSSI $(0 \mathrm{~m})$ and extending out into the hay meadows at distances of $150 \mathrm{~m}, 200 \mathrm{~m}, 250 \mathrm{~m}$ and 300 $\mathrm{m}$ from each of the three reference points. Two replicate transects were located in each of the 3 fields. The length of each transect was the same in all cases, and as long as possible whilst avoiding the proximity of field margins and hedgerows (Fig. 1). Only the northern transect posed a particular difficulty in this respect and required the $150 \mathrm{~m}$ sample point to be inside the SSSI. Fortunately at this distance the vegetation was adequately similar to the hay meadow; a dense sward of grass with a sparse flora of Asteraceae and cut once each year for the purposes of public amenity.

Samples were taken on 15 days between mid-May and the end of June during the three years from 2010 to 2012 inclusive. Of the 450 trap placements, $8(1.8 \%)$ were disturbed and the catch lost; no adjustment or compensation has been attempted for this error. The captured bees were identified to species following the classification of Archer (2004) and sorted by gender, size and nesting biology.

Bee size is expressed here as the intertegular span, which is the shortest distance across the thorax (mesonotum) between the wing bases (tegulae). This measurement has become a general standard for bee size, and being related to the volume of the wing muscle cavity, is especially relevant when comparing the flight capacity for different species of bee (Cane, 1987). Where span data were not available or insufficient for a particular species, measurements of museum specimens were made using a calibrated microscope. The intertegular span for each species was taken as the mean of a minimum of 15 specimens.

A Generalized Linear Model (Hastie \& Pregibon, 1992) within the statistical package "R" (R Core Team, 2012) was used as a multivariate technique to identify significant relationships within

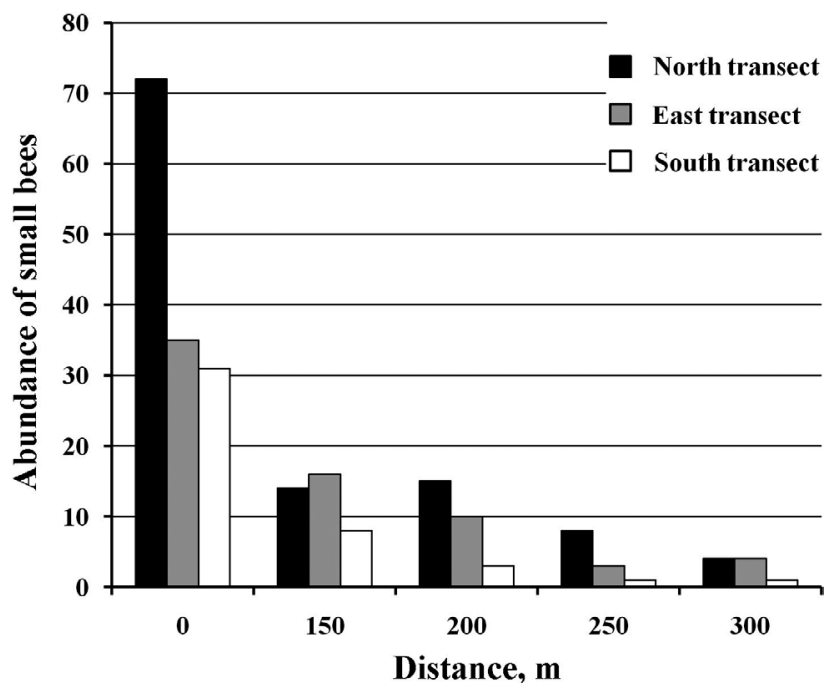

Fig. 3. Abundance of "small" bees in each of three sample directions, 2010-2012 (paired transects combined).

the data. The chosen model used the 442 individual water trap samples to derive parameters to describe the probability of a bee of a particular size occurring at a particular distance, field or transect replicate. As part of the linearization process a Poisson distribution was chosen to describe the probability of a bee arriving at a sampling location.

\section{RESULTS}

During the 3-year study a total of 49 species of ground nesting bee were recorded (Table 1). Fig. 2 shows the species diversity of ground nesting bees sampled across each of the three fields (north, east and south) with paired transects combined for each field. Table 1 and Fig. 2 show that species diversity was reasonably uniform across the area, with some reduction in diversity with increasing distance from the SSSI. However, the number of individuals is particularly variable.

The diversity and abundance of bee types was then further investigated by subdivision into quartiles of mean intertegular span $(<1.5 \mathrm{~mm}, 1.5-2.0 \mathrm{~mm}, 2.0-2.5 \mathrm{~mm}$, $>2.5 \mathrm{~mm}$ ) and the relationship for each form and quartile investigated with respect to their distribution along each transect. The critical quartile threshold at $1.5 \mathrm{~mm}$ was also investigated. It was found that only nest-provisioning females in the smallest quartile showed any coherent or significant trend (Fig. 3). The bee species in this quartile had intertegular spans ranging from $0.93 \mathrm{~mm}$ to $1.49 \mathrm{~mm}$ and are shown in Table 2. Males of nest-provisioning species

TABLE 1. Diversity and total abundance of nest-provisioning and cleptoparasite bees.

\begin{tabular}{|c|c|c|c|c|c|c|c|c|c|c|}
\hline \multirow{2}{*}{ Transect } & \multicolumn{2}{|c|}{$\begin{array}{l}\text { Females of nest-pro- } \\
\text { visioning species }\end{array}$} & \multicolumn{2}{|c|}{$\begin{array}{l}\text { Males of nest-pro- } \\
\text { visioning species }\end{array}$} & \multicolumn{2}{|c|}{$\begin{array}{l}\text { Females of clepto- } \\
\text { parasite species }\end{array}$} & \multicolumn{2}{|c|}{$\begin{array}{l}\text { Males of clepto- } \\
\text { parasite species }\end{array}$} & \multicolumn{2}{|c|}{ Overall totals } \\
\hline & $\begin{array}{c}\text { Bee } \\
\text { species }\end{array}$ & $\begin{array}{l}\text { Total } \\
\text { bees }\end{array}$ & $\begin{array}{c}\text { Bee } \\
\text { species }\end{array}$ & $\begin{array}{l}\text { Total } \\
\text { bees }\end{array}$ & $\begin{array}{c}\text { Bee } \\
\text { species }\end{array}$ & $\begin{array}{l}\text { Total } \\
\text { bees }\end{array}$ & $\begin{array}{c}\text { Bee } \\
\text { species }\end{array}$ & $\begin{array}{l}\text { Total } \\
\text { bees }\end{array}$ & $\begin{array}{c}\text { Bee } \\
\text { species }\end{array}$ & $\begin{array}{l}\text { Total } \\
\text { bees }\end{array}$ \\
\hline North Transect & 27 & 262 & 14 & 430 & 11 & 64 & 5 & 33 & 41 & 789 \\
\hline East Transect & 29 & 351 & 15 & 1128 & 9 & 37 & 6 & 27 & 41 & 1543 \\
\hline South Transect & 20 & 196 & 14 & 115 & 9 & 64 & 2 & 4 & 31 & 379 \\
\hline Transects combined & 33 & 809 & 18 & 1673 & 14 & 165 & 7 & 64 & 49 & 2711 \\
\hline
\end{tabular}




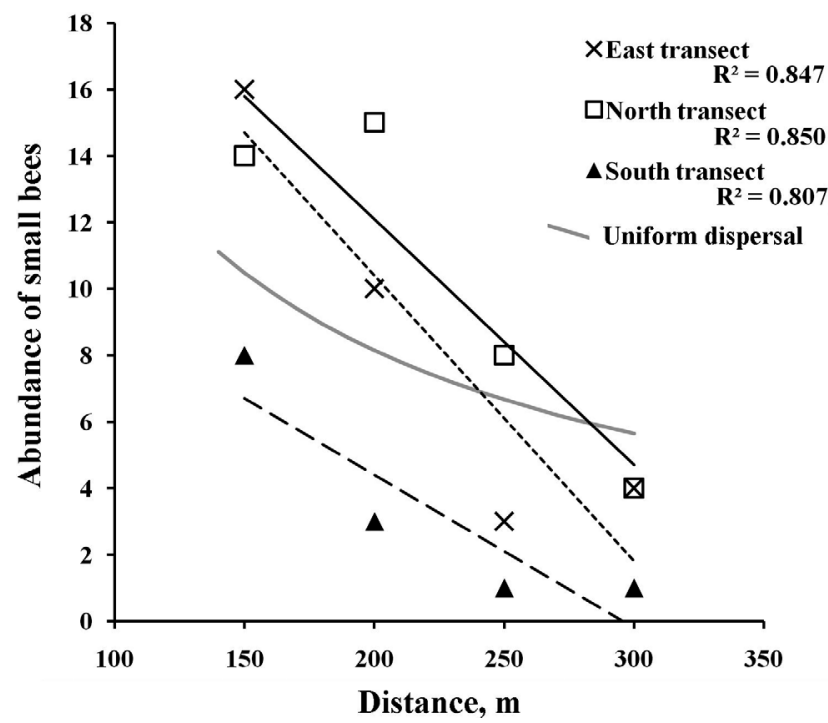

Fig. 4. Abundance of "small" bees in each of three fields, 2010-2012 (paired transects combined) together with an inverse square relationship for evenly dispersing individuals.

and cleptoparasites of both sexes indicated no significant trend by transect or combinations of transects. Females of nest-provisioning species in the three largest quartiles of intertegular span also showed no significant trend, other than a greater diversity of species within the SSSI.

In contrast to all other bee categories, the distribution and abundance of small female bees is particularly instructive. Most importantly, when the dominating abundance in the SSSI is excluded from the analysis, there remains a consistent decrease in small bee abundance with increasing distance from the SSSI. Combining all transects, the regression of small bee abundance to distance from the

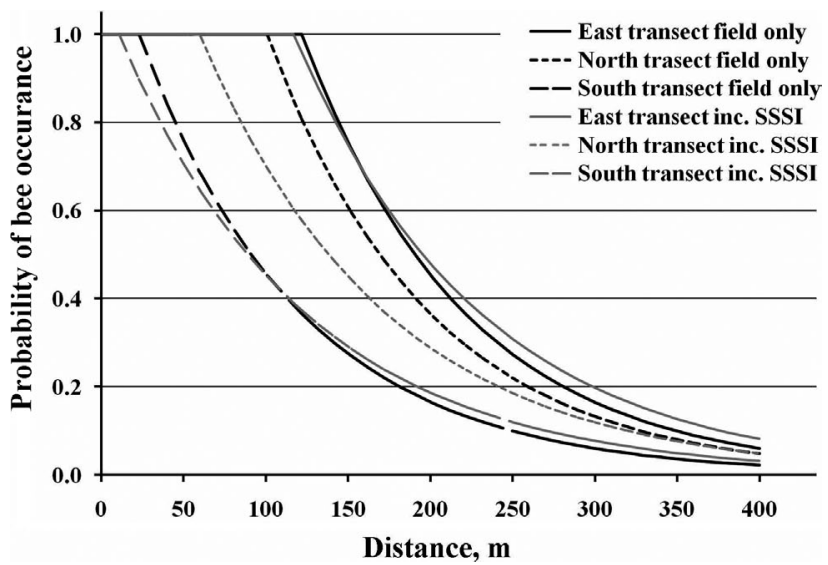

Fig. 5. Fitted curves describing the probability of a "small" bee occurring at a given distance from its nesting site for each of three fields; with and without including the abundance data for "small" bees at the nesting site.

SSSI, excluding the SSSI, had a gradient of $-0.206 \mathrm{~m}^{-1}\left(\mathrm{R}^{2}\right.$ $=0.946$ ) which is significant at the $5 \%$ level of probability. The next best fit for any other category of bee was for small male bees $\left(<1.5 \mathrm{~mm}\right.$ span), with $\mathrm{R}^{2}=0.600$, and is not significant at $10 \%$.

This result for small female bees is reinforced when the trend for each field is analyzed separately. Fig. 4 shows that, notwithstanding the apparent homogeneity of each field, the abundance of bees observed in all three demonstrates a similar and significant gradient of diminishing abundance with increasing distance from their corresponding areas of high nesting abundance within the SSSI. Although the habitats surrounding the transects are markedly heterogeneous and generally unsuitable for foraging bees (Fig. 1) it is important to note that, hypothetically, if bees were to

TABLE 2. Females of nest-provisioning bee species with an intertegular span $<1.5 \mathrm{~mm}$ and additional next largest species $>1.5 \mathrm{~mm}$. The taxonomic classification follows Archer (2004).

\begin{tabular}{|c|c|c|c|c|c|}
\hline Species & $\begin{array}{l}\text { Abundance } \\
\text { 2010-2012 }\end{array}$ & $\begin{array}{l}\text { Mean intertegular } \\
\text { span (mm) }\end{array}$ & $\begin{array}{c}\text { Standard error of the } \\
\text { mean span }(\mathrm{mm})\end{array}$ & $\begin{array}{l}\text { Mean span } \\
\text { sample size }\end{array}$ & Source* \\
\hline \multicolumn{6}{|l|}{ Smallest quartile $(0.93-1.49 \mathrm{~mm})$} \\
\hline Lasioglossum minutissimum (Kirby, 1802) & 28 & 0.930 & 0.0148 & 27 & SPMR \\
\hline Lasioglossum morio (Fabricius, 1793) & 64 & 1.084 & 0.0181 & 16 & SPMR/IRW \\
\hline Lasioglossum leucopus (Kirby, 1802) & 20 & 1.150 & 0.0330 & 18 & SPMR \\
\hline Lasioglossum pauxillum (Schenck, 1853) & 3 & 1.155 & 0.0208 & 20 & SPMR/IRW \\
\hline Lasioglossum smeathmanellum (Kirby, 1802) & 5 & 1.260 & 0.0080 & 55 & SPMR \\
\hline Lasioglossum punctatissimum (Schenck, 1853) & 30 & 1.293 & 0.0190 & 18 & SPMR/IRW \\
\hline Lasioglossum fulvicorne (Kirby, 1802) & 3 & 1.323 & 0.0190 & 16 & SPMR/IRW \\
\hline Lasioglossum villosulum (Kirby, 1802) & 13 & 1.375 & 0.0211 & 23 & SPMR/IRW \\
\hline Andrena minutula (Kirby, 1802) & 30 & 1.450 & 0.0263 & 18 & SPMR \\
\hline Andrena semilaevis Pérez, 1903 & 2 & 1.462 & 0.0079 & 25 & IRW \\
\hline Andrena subopaca Nylander, 1848 & 3 & 1.480 & 0.0239 & 16 & SPMR/IRW \\
\hline Halictus tumulorum (Linnaeus, 1758) & 23 & 1.490 & 0.0364 & 18 & SPMR \\
\hline \multicolumn{6}{|l|}{ Additional species $(>1.5 \mathrm{~mm})$} \\
\hline Lasioglossum quadrinotatum (Kirby, 1802) & 1 & 1.551 & 0.0169 & 17 & IRW \\
\hline Lasioglossum malachurum (Kirby, 1802) & 20 & 1.619 & 0.0322 & 18 & SPMR/IRW \\
\hline Lasioglossum albipes (Fabricius, 1781) & 1 & 1.647 & 0.0194 & 25 & IRW \\
\hline Lasioglossum calceatum (Scopoli, 1763) & 22 & 1.846 & 0.0328 & 20 & SPMR/IRW \\
\hline
\end{tabular}

* SPMR - data contributed by S.P.M. Roberts of Reading University Dept. of Agriculture; IRW - data contributed by I.R.Wright. 
disperse uniformly from a nesting site into a perfectly homogeneous landscape, their density would decrease as an inverse-square of the distance from the nest (Osborne et al., 2008). In the data presented here it is likely that there would be some component of decreasing abundance due to the dispersal of bees. However, the rates of decrease are steeper than for an inverse-square reduction, particularly for the east and north transects (Fig. 4) suggesting a different or additional influence. For the abundances shown here, an inverse-square relationship would also require much greater abundances at the nesting sites.

On the strength of this result, the abundance data for small female bees from all field transect points (two transects within each of three fields) was analyzed using a Generalised Linear Model (Hastie \& Pregibon, 1992) with parameters of distance, field and the transect pairing within each field. When analysed separately for each sample distance, the daily rate of capture of small bees was found to be well represented by a Poisson distribution in all cases $(p<0.05)$ with the exception of those at $150 \mathrm{~m}$. Consequently, the Poisson distribution was taken as a suitable model for the probability of a bee arriving at a given sample point.

When considering the data from the fields alone, i.e. excluding the SSSI data, the distance from the SSSI was highly significant (slope, $\mathrm{p}<0.001$; intercept, $\mathrm{p}<0.005$ ), and that the occurrence of bees in the south field was also significantly different $(\mathrm{p}<0.001)$ from that of the other two fields due to overall lower abundances. The north and east fields were not significantly different from each other $(p>0.1)$ and there was no significant difference $(p>0.1)$ between the pairs of transects within each of the fields. Using the modelled parameters for distance and the differences between fields, the probability of a small bee arriving at a sample point at a particular distance in each field is shown in Fig. 5.

Notwithstanding the significantly different habitat within the SSSI and the dominating abundance of bees at the principle nesting sites (at distance $0 \mathrm{~m}$, Fig. 3) when these data are added into the model most parameters are little changed. The probability model for the east and south transects remain effectively unchanged (Fig. 5), and only the north transect has changed in response to the particularly high abundance at its "zero" point. In this instance the three fields all had parameters that were significant $(p<0.001)$ and significantly different from one another $(\mathrm{p}<0.001)$.

The size range for "small" female bees was tested by increasing the upper threshold to include additional species. It was found that when the threshold intertegular span was increased from $1.50 \mathrm{~mm}$ to $1.62 \mathrm{~mm}$, to include Lasioglossum quadrinotatum (1 specimen) and L. malachurum (20 specimens) (see Table 2) some model parameters were significantly weaker (slope, $\mathrm{P}<0.001$; intercept, $\mathrm{p}<0.1$ ) and when further increased to $1.85 \mathrm{~mm}$ to include L. albipes (1 specimen) and L. calceatum (22 specimens) parameterisation ceased to be significant $(p>0.1)$ except for the difference between fields.

\section{DISCUSSION}

Only the females of nest-provisioning bee species, as central place foragers, are obliged to move between their nesting site and suitable sources of pollen; and the distance that separates these two partial habitats is critical for effective foraging and the successful rearing of larvae for the following year (Williams \& Kremen, 2007). Males of provisioning species and cleptoparasite bees of both sexes take no part in returning pollen to the nest, and are consequently not subjected to these critical provisioning flights. Therefore, if evidence for a relationship between bee size and flight capacity should be present in the sampling by this study, it would most likely be expressed in the data for the provisioning females. That the function appears in only the smallest of bees demonstrates that it is only these bees that have a limited flight capacity within the scale of the study. Larger ground-nesting bees with flight capacities greater than the scale of this study would be able to forage more freely within the study area, and consequently show no trend or pattern of distribution. The wide variation in abundances between species groups (Table 1) is mostly due to the mass emergence of particular species on some survey days, most notably males of larger solitary species such as Andrena cineraria (Linnaeus, 1758) and A. haemorrhoa (Fabricius, 1781).

To draw any conclusion from this study it is necessary to demonstrate that a dominant proportion of the smaller ground-nesting bees sampled in the fields are most probably nesting within the SSSI and travelling towards the fields for their pollen. Clearly if large numbers of small bees were nesting in the fields, or in the habitats in close proximity to the fields, the observed trends (Fig. 4) would have been obscured by bees nesting nearby or arriving from other directions. In this respect it is particularly important in this study that all three fields have shown the same trend, quite independently from each other, and notwithstanding their differences in character, aspect and overall bee abundance.

A further consideration for possible error would be heterogeneity within the bounds of each field which could contribute to the trends shown in Fig. 4. The only field to have a known change of character within its area is the south field, which is somewhat more sandy in the northwest corner compared the rest of the field. However, apart from some dampness at the change of geology there was no discernable difference in the abundance or diversity of flora in this corner. The other two fields had no discernable variation in flora, soil or dampness within their area. Similarly, any notional bias in the performance of water traps due to variations in floral distribution is considered to be negligible.

Although each field has a very different aspect with respect to the passage of the sun, it is the gently sloping south field that enjoyed the strongest insolation and yet had the lowest overall abundance of bees. The cause of this reduced abundance is not obvious, especially as the flora in this field is not wanting. However, it is possible that the loamy soil of the south field retains more moisture and 
therefore could be relatively cooler, making bee flight less efficient here, compared to the more freely draining soils of the other two fields.

The mature sandy habitats at the reference locations within the SSSI are quite different to those of the transect fields, having escaped cultivation for centuries, and the diversity of ground-nesting bees reflects this. Also these reference locations are somewhat different from each other, either in their flora [e.g. the extent of Ulex europaeus Linnaeus (Fabaceae)] the proportion of exposed soil or their soil type (fine or course-grained sands) and may contribute to the differences in abundances at these points during the study. However, considering these contrasts it is particularly interesting to note that the abundance of small nesting bees at the reference points is reasonably consistent with an extrapolation of the abundance functions from the fields; especially for the east and south fields (Fig. 5). That is, in two cases the optimised curves of bee occurrence across the fields are little changed when the higher abundance data from the SSSI are added. For the sample points that are closest to the SSSI the probability of bee occurrence is very variable, depending upon the abundance of bees at source, however at $300 \mathrm{~m}$ from the nesting area the probabilities are all in the more limited range 0.05-0.2. From this it could be inferred that in a landscape with a limited flora, there may be influences on foraging bees that cause their distribution to be somewhat independent of habitat detail, and with increasing distance from the nesting sites bee size and flight capacity become the dominant influences.

Grouping the diversity of bee species into four equal quartiles of size range was expedient for two reasons: a necessity to separate the larger bees for which there was no discernable relationship, and the data being insufficiently distributed to analyze by individual species. The choice of linear quartile ranges, based on intertegular span, conveniently gave a similar abundance and diversity in each quartile; in contrast to volumetric increments, for example, which would place over half of all bees in the first quartile. However, to eliminate any influence from this choice, it was necessary to investigate the upper threshold size for "small" bees (intertegular span $<1.5 \mathrm{~mm}$ ). This was achieved by incrementally introducing the next largest bees into the model for this quartile: Lasioglossum quadrinotatum, L. malachurum, L. albipes and L. calceatum. The results presented here suggest that bees with an intertegular span greater than $1.5 \mathrm{~mm}$ where equally likely to appear at any point along each transect and therefore are likely to have a flight capacity that is greater than the scale of this experiment.

Previous work to estimate the flight limitations of both solitary and social bees has mostly focussed on observing bees as they succeed or fail to undergo a non-natural journey imposed upon them as a surrogate of true foraging (Greenleaf et al., 2007). In this way it has been possible to build a functional relationship, species by species, between bee size and the exact distances attempted. By contrast, in this study we have sampled the natural occurrence of ground-nesting bees across a juxtaposition of habitats and distances, but without knowing the exact nesting location for each bee. The result from this study is therefore not concerned so much with species sampled, but with the behaviour of all bees of a particular size. Given these different approaches, direct comparison is not possible. Furthermore, this study presents a result for particularly small bees, typically less than $7 \mathrm{~mm}$ in length, for which there are very few studies. Although Käpylä (1978) gives a maximum foraging distance of $150 \mathrm{~m}$ for Chelostoma florisomne (Linnaeus, 1758) [= C. maxillosum (Linnaeus. 1767)] whose length is given as $5.5 \mathrm{~mm}$, most parameterised relationships between bee size and forage distance (Gathmann \& Tscharntke, 2002; Greenleaf et al., 2007) are derived from much larger bees (see for example Gathmann \& Tscharntke, 2002) and any comparison with this study would be an extrapolation.

To make a comparison between this study and those summarised by Greenleaf et al. (2007) it would be necessary to assume a numerical similarity between the probability of trapping a specific bee at a given distance from its nesting area (as in this study) and the probability of it successfully returning to its nest if released at that distance. With this assumption, for the bees in this study having an intertegular span of up to $1.5 \mathrm{~mm}$, the "Typical homing distance" at which $50 \%$ of bees were observed would be in the range 90-190 $\mathrm{m}$ and the "Maximum homing distance" at which $10 \%$ of small bees were observed would be $250-370$ m (Fig. 5).

The origin of this investigation was to observe the extent to which meadows that adjoin a designated wildlife site contributed resources for the aculeate Hymenoptera travelling from within the site; and has taken advantage of an arrangement of hay meadows that surround an established area of abundant and diverse aculeate nesting. The scope of the study was limited in size by the scale of the habitat mosaic, with fields typically $300-500 \mathrm{~m}$ in length and width. Furthermore, although the results are limited to the smallest of ground nesting bees, these pollinating insects are probably the least studied bees with respect to their ability to forage in the landscape.

The study has demonstrated that whilst the majority of larger bees forage relatively freely on this scale, the smallest of bees do not necessarily have the flight capacity to utilise the whole of an adjoining field. This phenomenon would be critical to the viability of the smaller species when pollen resources are limited, and an important consideration for conservation and agri-environment schemes that aim to plant new "pollen and nectar" forage areas in the landscape.

In a fragmented landscape, understanding the flight capacities of wild bees of different sizes is an important conservation consideration, especially when the habitat fragmentation is on a similar scale to maximum foraging distances. As with many other animals, bees depend on two or more, and often quite contrasting, partial habitats and although the quality of each habitat may seem particularly 
suitable, if the separation between them is too great then the dependent species will be compromised.

ACKNOWLEDGEMENTS. The authors are especially indebted to the University of Reading Centre for Agri-Environmental Research for overall guidance, the provision of intertegular span data and help with the experimental design. The authors' own measurements of intertegular span were facilitated by J. Hogan at the Oxford University Museum of Natural History, and processed with the assistance of S. Williams. The statistical analysis and linear modelling were designed by A. Bishop. The field work was made possible with the assistance of A. Halcro-Johnston, B. Harding, D. Tritton and J. Wright. Permission for access to survey in the various areas was generously given by D. Stogdale of Monk's Farm, Shotover, D. Walker of Manor Farm, Horspath and A. Roberts for "Brasenose Wood and Shotover Hill" Site of Special Scientific Interest. The authors are grateful to H. Roy for critical comment on the manuscript.

\section{REFERENCES}

Araújo E.D., Costa M., Chaud-Netto J. \& Fowler H.G. 2004: Body size and flight distance in stingless bees (Hymenoptera: Meliponini): inference of flight range and possible ecological implications. - Braz. J. Biol. 64: 563-568.

ARCHER M.E. 2004: BWARS Members' Handbook. Centre for Ecology and Hydrology, Wallingford, UK, 158 pp.

Bosch J., Kemp W.P. \& Trostle G.E. 2006: Bee population returns and cherry yields in an orchard pollinated with Osmia lignaria (Hymenoptera: Megachilidae). - J. Econ. Entomol. 99: 408-413.

CANE J.H. 1987: Estimation of bee size using intertegular span (Apoidea). - J. Kans. Entomol. Soc. 60: 145-147.

Corbet S.A., Williams I.H. \& Osborne J.L. 1991: Bees and the pollination of crops and wild flowers in the European Community. - Bee World 72: 47-59.

Cresswell J.E., Osborne J.L. \& Goulson D. 2000: An economic model of the limits to foraging range in central place foragers with numerical solutions for bumblebees. - Ecol. Entomol. 25: 249-255.

Fabre J.H. 1914: The Mason Bees. Dodd, Mead and Co., New York, $315 \mathrm{pp}$.

Franzén M. \& Larsson M. 2007: Pollen harvesting and reproductive rates in specialized solitary bees. - Ann. Zool. Fenn. 44: 405-414.

Gathmann A. \& TscharntKe T. 2002: Foraging ranges of solitary bees. - J. Anim. Ecol. 71: 757-764.

Gathmann A., Greiler H.-J. \& Tscharntke T. 1994: Traps nesting bees and wasps colonising set-aside fields: succession and body size, management by cutting and sowing. - Oecologia 98: 8-14.

Goulson D. 2010: Bumblebees; their Behaviour, Ecology and Conservation. Oxford University Press, Oxford, $317 \mathrm{pp}$.

Goulson D., Lepais O., O’Connor S., Osborne J.L., Sanderson R.A., Cussans J., Goffe L. \& Darvill B. 2010: Effects of land use at a landscape scale on bumblebee nest density and survival. - J. Appl. Ecol. 46: 1207-1215.

Greenleaf S.S., Williams N.M., Winfree R. \& Kremen C. 2007: Bee foraging ranges and their relationships to body size. Oecologia 153: 589-596.

Gregory S.J. \& WRIGHT I.R. 2005: Techniques to enhance the habitat of ground-nesting solitary bees and wasps. - British Wildlife 6: 408-409.

Guedot C., Bosch J. \& Kemp W.P. 2009: Relationship between body size and homing ability in the genus Osmia (Hymenoptera: Megachilidae). — Ecol. Entomol. 34: 158-161.
Hastie T.J. \& Pregibon D. 1992: Generalized linear models. In Chambers J.M. \& Hastie T.J. (eds): Statistical Models. Wadsworth \& Brooks, Cole, pp. 195-248.

Holzschun A., Steffan-Dewenter I., Kleijn D. \& TscharntKe T. 2007: Diversity of flower-visiting bees in cereal fields: effects of farming system, landscape composition and regional context. - J. Appl. Ecol. 44: 41-49.

Horton A., Sumbler M.G., Cox B.B. \& Ambrose K. 1995: Geology of the Country around Thame. Memoir of the British Geological Survey, Sheet 237 (England and Wales). HMSO, London, 169 pp.

JHA S. \& KREMEN C. 2012: Resource diversity and landscape-level homogeneity drive native bee foraging. - Proc. Natl. Acad. Sci. U.S.A. 110: 555-558.

KÄPYLÄ M. 1978: Foraging distance of a small solitary bee, Chelostoma maxillosum (Hymenoptera, Megachilidae). Ann. Entomol. Fenn. 44: 63-64.

Kremen C., Williams N.M. \& Thorp R.W. 2002: Crop pollination from native bees at risk from agricultural intensification. Proc. Natl. Acad. Sci. U.S.A. 99: 16812-16816.

Krunić M. \& Stanisavljević L. 2006: Augmentation of managed populations of Osmia cornuta and $O$. rufa (Hymenoptera: Megachilidae) in Southeastern Europe. - Eur. J. Entomol. 103: 695-697.

Osborne J.L., Clark S.J., Morris R.J., Williams I.H., Riley J.R., Smith A.D., ReYnolds D.R. \& Edwards A.S. 1999: A landscape scale study of bumble bee foraging range and constancy, using harmonic radar. - J. Appl. Ecol. 36: 519-533.

Osborne J.L., Martin A.P., Carreck N.L., Swain J.L., Knight M.E. \& Goulson D. 2008: Bumblebee flight distances in relation to the foraging landscape. - J. Anim. Ecol. 77: 406-415.

Peterson J.H. \& Roitberg B.D. 2006: Impacts of flight distance on sex ratio and resource allocation to offspring in the leafcutter bee, Megachile rotundata. - Behav. Ecol. Sociobiol. 59: 589-596.

R Core Team 2012: R: A language and Environment for Statistical Computing. R Foundation for Statistical Computing, Vienna, Austria.

Salzman L.P. (ed.) 1939: Victoria County History of Oxfordshire. Vol. 1. Oxford University Press, 497 pp.

Steel D. 1984: Shotover: The Natural History of a Royal Forest. Pisces Publications, Oxford, $120 \mathrm{pp}$.

ToRchio P.H. 1976: Use of Osmia lignaria (Hymenptera: Apoidea, Megachilidae) as a pollinator in an apple and prune orchard. J. Kans Entomol. Soc. 49: 475-482.

Tscharntke T., Gathmann A. \& Steffan-Dewenter I. 1998: Bioindication using trap-nesting bees and wasps and their natural enemies: community structure and interactions. - J. Appl. Ecol. 35: 708-719.

van Nieuwstadt M.G.L. \& Ruano Iraheta C.E. 1996: Relation between size and foraging range in stingless bees (Apidae, Melipoinae). - Apidologie 27: 219-228.

Walther-Hellwig K. \& Frankl R. 2000: Foraging habitats and foraging distances of bumblebees, Bombus spp. (Hym., Apidae), in an agricultural landscape. - J. Appl. Entomol. 124: 299-306.

Westphal C., Bommarco R., Carré G., Lamborn E., Morison N., Petanidou T., Potts S.G., Roberts S.P.M., Szentgyörgyi H., Tscheulin T., Vaissière B.E., Woyciechowski M., BiesmeiJER J.C., Kunin W.E., Settele J. \& Steffan-Dewenter I. 2008: Measuring bee diversity in different European habitats and biogeographical regions. - Ecol. Monogr. 78: 653-671.

WESTRICH P. 1996: Habitat requirements of central European bees and problems of partial habitats. In Matheson A., Buchmann S.L., O'Toole C., Westrich P. \& Williams I.H. (eds): The Con- 
servation of Bees. Linnaean Society Symposium Series 18 . Academic Press, London, UK, pp. 1-16.

Williams I.H. 1996: Aspects of bee diversity and crop pollination in the European Union. In Matheson A., Buchmann S.L. O'Toole C., Westrich P. \& Williams I.H. (eds): The Conservation of Bees. Linnaean Society Symposium Series 18. Academic Press, London, UK, pp. 210-226.

Williams N.M. \& Kremen C. 2007: Resource distributions among habitats determine solitary bee offspring production in a mosaic landscape. - Ecol. Appl. 17: 910-921.
Wright I.R. \& GREgory S.J. 2006: The aculeate Hymenoptera of Shotover Hill, Oxfordshire. - Br. J. Entomol. Nat. Hist. 19: 65-76.

Zurbuchen A., Cheesman S., Klaiber J., Müller A., Hein S. \& Dorn S. 2010: Long foraging distances impose high costs on offspring in solitary bees. - J. Anim. Ecol. 79: 674-681.

Received July 15, 2014; revised and accepted January 6, 2014 Prepublished online January 22, 2015 